\title{
Adar1 deletion causes degeneration of exocrine pancreas via Mavs-dependent interferon signaling
}

Dhwani N. Rupani ${ }^{1,2}$, Robert W. Cowan ${ }^{2,3}$, Fredrik I. Thege $e^{2,4}$, Vidhi Chandra ${ }^{1}$, Sonja M. Wörmann ${ }^{2,4}$, Hajar Rajaei ${ }^{1}$, Prerna Malaney ${ }^{5}$, Olivereen Le Roux ${ }^{1}$, Sara L. Manning ${ }^{2,3}$, Jack Hashem $^{2,3}$, Jennifer Bailey-Lundberg ${ }^{6,7}$, Florencia McAllister ${ }^{1,8,9^{*}}$, Andrew D. Rhim ${ }^{2,3^{*}}$

${ }^{1}$ Department of Clinical Cancer Prevention, The University of Texas MD Anderson Cancer Center, Houston, TX 77030, USA

${ }^{2}$ Sheikh Ahmed Cancer Center for Pancreatic Cancer Research, The University of Texas MD Anderson Cancer Center, Houston, TX 77030, USA

${ }^{3}$ Department of Gastroenterology, Hepatology \& Nutrition, The University of Texas MD Anderson Cancer Center, Houston, TX 77030, USA

${ }^{4}$ Department of Translational Molecular Pathology, The University of Texas MD Anderson Cancer Center, Houston, TX 77030, USA

${ }^{5}$ Department of Leukemia, The University of Texas MD Anderson Cancer Center, Houston, TX 77030, USA

${ }^{6}$ Department of Anesthesiology, Center for Perioperative Medicine, McGovern Medical School, The University of Texas Health Sciences Center, Houston, TX 77030, USA

${ }^{7}$ Center for Interventional Gastroenterology at UTHealth (iGUT), McGovern Medical School, Houston, TX 77030

${ }^{8}$ Gastrointestinal Medical Oncology, The University of Texas MD Anderson Cancer Center, Houston, TX 77030, USA

${ }^{9}$ Department of Immunology, The University of Texas MD Anderson Cancer Center, Houston, TX 77030, USA 
${ }^{*}$ Corresponding authors:

Andrew D. Rhim, MD

Department of Gastroenterology, Hepatology \& Nutrition

The University of Texas MD Anderson Cancer Center

1515 Holcombe Blvd., Unit 1466

Houston, TX 77030, United States

arhim@mdanderson.org

Florencia McAllister, MD

Department of Clinical Cancer Prevention

The University of Texas MD Anderson Cancer Center

1515 Holcombe, Unit 1360,

Houston, TX, 77030, United States

fmcallister@mdanderson.org

Running title: Role of Adar1 in pancreatic development and homeostasis

Keywords: pancreatic development, pancreatic homeostasis, Adar1, Interferon, Mavs.

\section{Summary statement}

This work defines the role of Adar1 in pancreatic development and homeostasis.

\section{Author contributions}

D. Rupani designed, performed experiments and wrote the manuscript. R. Cowan, F. Thege, V.

Chandra, S. Wörmann, H. Rajaei, O. Le Roux, S. Manning, J. Hashem performed experiments.

R.Cowan, V. Chandra, P. Malaney and J. Bailey contributed to manuscript editing and revision.

A. Rhim conceptualized the project, designed experiments and supervised the work. F. McAllister designed experiments, supervised the work and wrote the manuscript. 


\section{ABSTRACT}

2 Adenosine deaminase acting on RNA 1 (ADAR1) is an RNA-binding protein that deaminates

3 adenosine $(\mathrm{A})$ to inosine(I). A-to-I editing alters post-transcriptional RNA processing making

4 ADAR1 a critical regulator of gene expression. Consequently, Adar1 has been implicated in

5 organogenesis. To determine the role of Adar1 in pancreatic development and homeostasis, we

6 specifically deleted Adar1 from the murine pancreas $\left(P t f 1 a^{C r e /+} ;\right.$ Adar1 $\left.^{\text {FlFI }}\right)$. The resulting mice

7 had stunted growth likely due to malabsorption associated with exocrine pancreas insufficiency.

8 Analyses of pancreases revealed ductal expansion, heightened interferon-stimulated gene

9 expression and an increased influx of immune cells. In addition, we observed an increased

10 prevalence of $\mathrm{CD}^{+} \mathrm{T}$ and natural killer cells in their splenic tissue. These results indicate an

11 association between loss of pancreatic Adar1 with dysregulation of systemic immunity.

12 Concurrent deletion of Adar1 and Mavs, a signaling protein implicated in the innate immune

13 pathway rescued the degenerative phenotype and resulted in normal pancreatic development.

14 Taken together, our work suggests that the primary function of Adar1 in the pancreas is to

15 prevent aberrant activation of the Mavs-mediated innate immune pathway, thereby maintaining

16 pancreatic homeostasis. 


\section{INTRODUCTION}

Epigenetic alterations to RNA are widespread and can influence numerous cellular processes (Roundtree et al., 2017). RNA editing is an epigenetic modification wherein RNA nucleoside bases are modified by cellular enzymes. Adenosine-to-inosine (A-to-I) editing is the most prevalent form of RNA editing, in which A-to-I hydrolytic deamination is catalyzed by adenosine deaminase acting on RNA (ADAR) enzymes (Eisenberg and Levanon, 2018).

In mammals, there are three Adar proteins. Adar1 is expressed ubiquitously in all tissues (Kim et al., 1994) while Adar2 and Adar3 are primarily expressed in the brain (Melcher et al., 1996). Adar1 encodes a constitutively expressed p110 isoform, localized in the nucleus, and an interferon-inducible p150 isoform that shuttles between the nucleus and cytoplasm (Patterson and Samuel, 1995).

Adar proteins have nonredundant functions, as demonstrated by the different phenotypes of Adar $^{1^{-/}}$, Adar2 ${ }^{-/}$, and Adar3 ${ }^{-/-}$mice. Adar1 is essential for murine embryogenesis

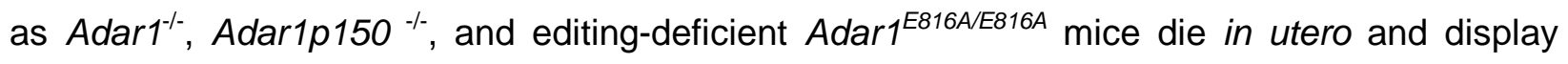
overexpression of interferon-stimulated genes (ISGs) (Wang et al., 2004, Hartner et al., 2004, Liddicoat et al., 2015, Ward et al., 2011). Moreover, these mice display widespread apoptosis, liver disintegration, and impaired hematopoiesis. In the absence of Adar1-mediated editing, melanoma differentiation-associated protein 5 (Mda5; encoded by Ifih1), a pattern recognition receptor, recognizes unedited endogenous RNA (Ahmad et al., 2018) and activates mitochondrial anti-viral signaling (Mavs) protein, its downstream effector. Mavs-related pathways include induction of ISGs and stimulation of innate immunity. Adar1 is a specific negative regulator of the Mda5-Mavs pathway and as such, Adar1 $1^{-/-}$Mavs $^{-/-}$and Adar1 $1^{-/-}$Ifih $^{-{ }^{-/}}$ mice do not exhibit exaggerated ISG expression and can be rescued to birth (Mannion et al., 2014, Pestal et al., 2015). 
Adar1 exerts Mavs-dependent and independent functions as Adar1 ${ }^{-/-}$Mavs $^{-/-}$mice exhibit

59 developmental defects in the kidney and spleen among other organs (Pestal et al., 2015). Mavs-

60 dependent functions are predicted to be RNA editing-mediated, whereas Mavs-independent

61 functions are attributed to the regulation of microRNA biogenesis (Ota et al., 2013), RNA

62 processing (Bahn et al., 2015), and protein recoding (Pestal et al., 2015). Organ-specific

63 knockout models have revealed that Adar1 is essential for development and homeostasis of the

64 liver, thymus, and hematopoietic compartment (Ben-Shoshan et al., 2017, Wang et al., 2015,

65 Hartner et al., 2009, Vongpipatana et al., 2020); however, its role in the pancreas remains

66 unknown.

67 The pancreatic exocrine compartment consists of highly specialized acinar cells that 68 synthesize zymogens (amylase, lipase, trypsin, and chymotrypsin) necessary for digestion, and

69 ductal cells that express carbonic anhydrase and secrete bicarbonate, which aids in neutralizing

70 acidic chyme and pancreatic juice in the duodenum (Cano et al., 2007, Grapin-Botton, 2005).

71 The islets of Langerhans comprise the pancreatic endocrine compartment, which produce

72 hormones to regulate blood glucose levels (Pandiri, 2014).

73 We sought to determine Adar1's role in pancreatic development and homeostasis by 74 conditionally deleting Adar1 from the pancreas.

\section{RESULTS and DISCUSSION}

78 Pancreas-specific Adar1 deletion results in a runted phenotype and progressive exocrine

79 pancreatic degeneration

Pancreas-associated transcription factor 1a (Ptf1a) is expressed on embryonic day 10.5

81 (E10.5) in multipotent pancreatic progenitors (Kawaguchi et al., 2002). To understand Adar1's

82 role in pancreatic development and homeostasis, we generated mice with the following

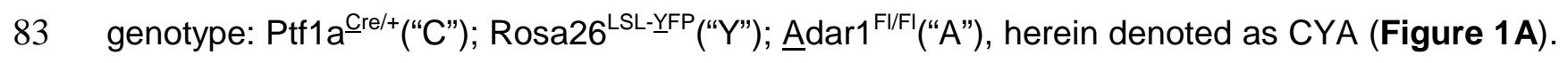


84 Adar1 recombination was detected in the CYA pancreas (Figure 1B), but not in the spleen or

85 kidney (Figure S1A), confirming the organ-specificity of the genetic model. At birth, control and

86 CYA mice were indistinguishable in appearance; however, pancreas-specific Adar1 deletion led

87 to a runted phenotype evident at day 4 (D4) postpartum (Figure S1B), and very prominent at

88 D21 (Figure 1C). Notably, CYA mice had significantly lower body mass compared to controls

89 (Figure 1D). At E18.5 and at birth, the CYA mice were present at expected Mendelian ratios,

90 which excluded the possibility of embryonic lethality (Figure S1C).

91 We next isolated and evaluated pancreatic tissue. Compared to controls, CYA mice had

92 visibly smaller pancreases at D10 and D21, but not at D0 (Figures 1E and S1D). At D21, the

93 relative pancreatic mass of CYA mice was significantly lower compared to controls (Figure 1F).

94 Likewise, at D21, the relative splenic mass, but not kidney mass, was reduced in CYA mice

95 compared to controls (Figure 1G). We noted $\mathrm{YFP}^{+}$cells in both the endocrine (insulin ${ }^{+}$) and

exocrine compartment of the pancreas; however, the YFP ${ }^{+}$area in the CYA pancreas was

97 markedly reduced compared to controls (Figure $\mathbf{1 H}$ and I).

To understand if reduced pancreatic mass is a result of defective development or progressive degeneration, we assessed the control and CYA pancreases microscopically at

100 E18.5, D2, D10, and D21. Histopathological analysis showed that the acinar cell area in CYA

101 mice was comparable to that in controls at E18.5; however, it significantly reduced by D2

102 (Figures 2A and B). Additionally, CYA pancreases exhibited an increase in duct-like structures 103 and an extensive immune infiltrate. Therefore, we stained for keratin19 (Ck19), a ductal cell 104 marker, and observed an increase in the number of Ck19+ clusters in the CYA pancreases 105 compared to controls at D10 (Figures 2C and D). We observed a similar amylase ${ }^{+}$area $^{-}$ 106 (exocrine pancreas) in control and CYA pancreases at E18.5, however by D21 the exocrine 107 area in CYA mice was drastically lower, confirming the progressive loss of the acinar cell area 108 (Figures 2E and F). A higher number of apoptotic nuclei was observed in the CYA pancreases 109 compared to controls at D21 (Figures 2G and H), which suggests that the decreased 
110 pancreatic mass in the CYA mice is attributable to apoptosis. Lastly, to quantify immune

111 infiltrate observed via histology, we stained for CD45, a pan-leukocyte marker, and observed a 112 significantly higher number of $\mathrm{CD} 45^{+}$cells in CYA pancreases compared to controls at D21

113 (Figures $2 \mathbf{l}$ and $\mathbf{J}$ ). Our results suggest that the CYA pancreases develop normally; however,

114 Adar1 is required for pancreatic acinar cell homeostasis and that the loss of Adar1 leads to 115 progressive and rapid pancreatitis, and pancreatic degeneration due to apoptosis.

\section{Loss of Adar1 results in exocrine pancreatic insufficiency and malabsorption}

118 Since the pancreas is required for digestion of food and blood glucose homeostasis, we 119 hypothesized that pancreatic degeneration results in dysfunction contributing to the runted 120 phenotype of CYA mice. Thus, we assessed whether loss of Adar1 affects the pancreatic 121 exocrine and endocrine compartments equally. Surprisingly, we observed a relative increase in 122 the insulin ${ }^{+}$area (endocrine compartment) of the CYA pancreases compared to controls (Figure 123 S2A and B), very likely due to their lower total pancreatic area. In our model, loss of Adar1 124 specifically affects the pancreatic exocrine but not endocrine compartment, which is not 125 unusual, as it has been previously reported that cells arising from common progenitors have a 126 differential response to Adar1 deletion (Gacem et al., 2020, Liddicoat et al., 2016). However, we 127 analyzed the pancreas at D21 and effects of Adar1 deletion on the endocrine compartment may 128 be apparent at later time points. Role of Adar1 in the pancreatic endocrine compartment can be 129 further studied using an endocrine-specific Cre (Magnuson and Osipovich, 2013).

$130 \quad$ Pancreatic injury results in alteration of serum pancreatic enzymes and hormone 131 concentrations (Lee and Papachristou, 2019, Galicia-Garcia et al., 2020), thus we next 132 assessed their concentration in the mice. CYA mice exhibited significant reduction in serum 133 lipase concentration but similar amylase, glucagon and insulin concentrations (Figure S2C-F) 134 compared to controls at D21. We predicted that decreased lipase concentration would hinder 135 digestion of complex triglycerides and fat absorption from the intestine resulting in higher-than- 
136 normal stool fat content, known as steatorrhea. Indeed, fecal fat content from CYA stool

137 samples had a significantly higher number of unabsorbed fat globules than control samples, in

138 which unabsorbed fat was absent (Figure S2G-H). Our results suggest that loss of Adar1

139 causes pancreatic exocrine insufficiency, leading to malabsorption and steatorrhea, symptoms

140 reminiscent of patients suffering from pancreatic insufficiency (Lindkvist, 2013). The

141 malabsorption of nutrients suggests that CYA mice are malnourished and provides an

142 explanation for their runted phenotype

144 Pancreas-specific Adar1 knockout induces systemic immune dysregulation

145 The CYA spleens were significantly smaller (splenic hypoplasia) compared to those of

146 controls (Figure 1G), thus we evaluated whether this was due to increased apoptosis but found

147 no difference in the number of apoptotic nuclei (Figures S3A and B). The spleen can initiate

148 immune responses in recognition of host damage or infection (Lewis et al., 2019); therefore, we

149 assessed whether the CYA spleens had an aberrant immune cell composition. We observed a

150 significantly higher proportion of $\mathrm{CD}^{+} \mathrm{T}$ cells and NK cells in CYA spleens compared to

151 controls (Figures S3C, D and S4). Loss of Adar1 is associated with type 1 interferon signaling

152 (Wang et al., 2015, Hartner et al., 2009), which modulates T and NK cell responses (McNab et

153 al., 2015, Brinkmann et al., 1993, Madera et al., 2016). Aberrant numbers of CD4 ${ }^{+}$T cells and

154 NK cells are implicated in numerous autoimmune disorders (Palmer and Weaver, 2010,

155 Skapenko et al., 2005, Liu et al., 2021). Due to the anatomical proximity of the pancreas and

156 spleen, certain chemokines and cytokines released from the Adar1 knockout pancreas could be

157 leading to splenic hypoplasia and changes in the lymphocyte population, though they remain to

158 be identified. Our findings suggest that loss of Adar1 in pancreas results in local inflammation

159 that triggers systemic immune activation. 


\section{Concurrent deletion of Mavs prevents the pancreatic degeneration caused by the loss of}

$162 \quad$ Adar1

163 Adar1 deletion stimulates a Mavs-mediated innate immune pathway and induces

164 expression of ISGs in Adar1 $^{-1-}$ mice (Mannion et al., 2014, Pestal et al., 2015). We found a 165 higher expression of ISGs in CYA pancreases compared to controls at D2 (Figure 3A), 166 consistent with activation of the Mavs pathway. Adar1 has a Mavs-dependent role in innate

167 immune activation, and its Mavs-independent functions can influence murine organ 168 development (Vongpipatana et al., 2020, Pestal et al., 2015). Therefore, we hypothesized that 169 co-deletion of Mavs would prevent innate immune activation and suppress aberrant ISG 170 expression, but that pancreas may still have developmental defects as described in other 171 organs. Accordingly, we generated mice with double knockout of Adar1 and Mavs from the

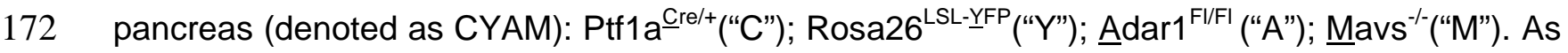
173 expected, ISG expression in CYAM mice was similar to controls, except Mx1 which was 174 significantly lower (Figure 3B). Surprisingly, CYAM mice developed similarly to the control mice.

175 Macroscopically, concurrent deletion of Mavs rescued the runted phenotype of CYA mice, and 176 CYAM body mass did not differ from controls at 6 or 12 months (Figures 3C, 3D and S5A). We 177 monitored CYAM mice for 12 months for delayed developmental defects, but none were noted.

178 Furthermore, there was no difference in the relative pancreatic mass of CYAM and control mice 179 at 6 or 12 months (Figures 3E, 3F, and S5B). To exclude the possibility that CYAM pancreases 180 developed normally because they expressed Adar1, we confirmed Adar1 recombination in the 181 pancreas at 2 months (Figure 3G). Microscopic examination of the CYAM pancreases showed 182 normal architecture devoid of apoptotic cells or excess immune infiltrate (Figures. $3 \mathbf{H}-\mathbf{L}$ ). Our 183 work suggests that concurrent Mavs knockout completely rescues the degenerative phenotype 184 of the CYA mice, and that CYAM pancreases develop normally. However, we cannot exclude 185 the possibility of transcriptomic differences or changes in protein translation in CYAM mice 186 (Bajad et al., 2020). 
Additionally, we generated mice heterozygous for Mavs, denoted as CYAM ${ }^{+/-}$. The body mass of $\mathrm{CYAM}^{+-}$mice was comparable to that of control and CYAM mice at 12 months (Figure S5A), however, their relative pancreatic mass was significantly lower (Figure S5B). Microscopic examination showed a significantly reduced acinar cell area in the $\mathrm{CYAM}^{+/-}$pancreases

191 compared to controls (Figure S5C and D). Our results suggest that concurrent deletion of Mavs

192 can rescue the degenerative phenotype observed in CYA mice, but presence of even one Mavs

193 allele can sub-optimally trigger innate immunity pathways leading to slower pancreatic 194 degeneration in the absence of Adar1.

\section{Co-deletion of Mavs restores pancreatic function that is disrupted by Adar1 deletion}

Since we determined that the CYAM pancreases were similar to those of controls in appearance and histology, we next evaluated whether CYAM mice had any deficiencies arising from pancreatic dysfunction. Therefore, we assessed whether the pancreatic exocrine and endocrine compartments had developed normally in CYAM mice. Immunohistochemistry analysis showed similar exocrine and endocrine area in the CYAM mice compared to controls

202 (Figure 4A-D). We then evaluated serum amylase, lipase and glucagon concentrations.

203 Contrary to results from CYA mice, serum lipase concentrations were comparable between

204 CYAM mice and controls (Figure 4E-G), suggesting that Mavs deletion rescued the pancreatic

205 dysfunction of CYA mice. Additionally, we tested pancreatic function by conducting oral glucose

206 tolerance tests (Andrikopoulos et al., 2008) and assessing fat absorption from the intestine

207 (Drummey et al., 1961). When challenged with glucose, both groups were equally adept at 208 insulin secretion and maintenance of glucose homeostasis (Figure $\mathbf{4 H}$ and I). In contrast to 209 steatorrhea observed in CYA mice, we did not observe any unabsorbed fat globules in the 210 stools of the CYAM mice (Figure $\mathbf{4 J}$ ). Using these criteria, our results suggest that CYAM 211 pancreases have no functional deficiencies. 
To our knowledge this is the first study that reports the pancreatic function of Adar1. The

213 absence of Adar1 in pancreatic cells leads to induction of ISGs and pancreatitis, similar to type I

214 interferonopathies observed in patients suffering from Aicardi-Goutieres syndrome, a subset of

215 which harbor ADAR1 genetic mutations (Crow and Manel, 2015). Our results are also in

216 accordance with previous studies, which have reported increased apoptosis and ISG expression

217 in Adar1 $^{-/}$mice and in organ-specific Adar1 knockout models (Ben-Shoshan et al., 2017,

218 Hartner et al., 2004, Hartner et al., 2009, Wang et al., 2004). Counter to Adar1's previously

219 reported role in the development of thymus, kidney and spleen (Pestal et al., 2015,

220 Vongpipatana et al., 2020), our investigation suggests that loss of Adar1 does not affect

221 pancreatic development. Our results indicate that Adar1 has a unique function in different cell

222 lineages and that its functions in one organ cannot be extrapolated to another organ.

223 In summary, our work shows that the Mavs-mediated function of Adar1 is essential for

224 homeostasis and the suppression of interferon signaling in the pancreas.

\section{MATERIALS AND METHODS}

227 Mouse models

228 A pancreas-specific Adar1 knockout model was generated by crossing the Adar1 floxed allele

229 (Adar1 $\left.{ }^{F /} ; " A "\right) \quad(M u t a n t$ Mouse Resource \& Research Centers stock no: 34619-JAX) with the 230 pancreas-specific Ptf1a ${ }^{\text {Cre/+}}$ ("C") model (Kawaguchi et al., 2002). Genotyping and Adar1

231 recombination assessment were performed as described previously (Wang et al., 2004). The

232 Rosa26 $6^{L S L-\underline{Y} F P}$ (“Y”) reporter allele (The Jackson Laboratory, Stock No: 006148) was introduced

233 to enable lineage tracing (Srinivas et al., 2001, Rhim et al., 2012). Mavs $^{-/}$(“M”) mice (Sun et al.,

234 2006) were obtained from The Jackson Laboratory (stock no: 008634) and genotyped according

235 to the protocols available on their website. For a pancreas-specific Adar1 knockout, we

236 generated Ptf1a $\mathrm{C}^{\mathrm{Cre} /+}$ ("C"); Rosa26 $6^{\mathrm{LSL}-\underline{Y F P}}$ (“Y”); $\underline{\text { Adar1 }}{ }^{\mathrm{Fl} / \mathrm{FI}}$ ("A”) mice, herein denoted as CYA. For a

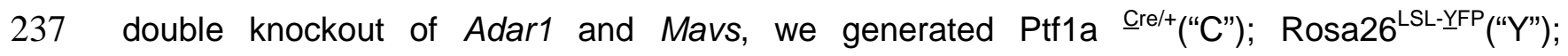


238 Adar1 ${ }^{\mathrm{Fl} / \mathrm{FI}}$ (“A”); Mavs $^{-/-}$("M") mice, herein denoted as CYAM. The controls used are either CYA ${ }^{\mathrm{F+}}$,

$239 \mathrm{CY}, \mathrm{YA}^{\mathrm{FF}}, \mathrm{CYM}$ or $\mathrm{M}^{-/}$. All animal experiments were conducted in compliance with the National

240 Institutes of Health guidelines for animal research and were approved by the Institutional Animal

241 Care and Use Committee of The University of Texas MD Anderson Cancer Center.

\section{Histopathology}

244 Mice were euthanized, their tissues were isolated and weighed. For relative organ mass (\% 245 organ mass/body mass) was calculated for each mouse. Tissues were then fixed in zinc246 formalin and embedded in paraffin, and $5-\mu \mathrm{m}$ sections were obtained and stained with

247 hematoxylin (Dako) and eosin (VWR) following standard protocols.

249 Immunohistochemistry

250 Formalin-fixed, paraffin-embedded tissue sections were deparaffinized in xylene and rehydrated

251 in graded ethanol. Antigen retrieval was performed in a citrate buffer $(\mathrm{pH} 6.0)$. Slides were

252 treated with $3 \%$ hydrogen peroxide for 15 min and blocked for an hour with either CAS-block

253 (ThermoFisher; \#8120) or $2.5 \%$ goat serum. Tissue sections were incubated overnight at $4^{\circ} \mathrm{C}$

254 with primary antibodies against mouse amylase, insulin, keratin19 and CD45 (antibody details,

255 including dilutions, can be found in Table S1). A SignalStain DAB Substrate Kit (Cell Signaling

256 Technology) was used for chromogenic antibody detection. Slides were counterstained with

257 hematoxylin and mounted in Acrymount (StatLab). Apoptotic nuclei were detected according to

258 the manufacturer's instructions using an in situ apoptosis detection kit (Abcam, \#ab206386)

259 which utilizes principals of the terminal deoxynucleotidyl transferase nick-end labeling (TUNEL)

260 assay.

261 Slides were imaged at 20X magnification on the Aperio CS2 Scanner and analyzed with the 262 Aperio eSlide Manager software. 
263 Positive cells/staining area were quantified and normalized to the total pancreatic area per field

264 of view. A minimum of 5 different fields were assessed, and the average number of positive 265 cells/area for each biological replicate was reported.

267 Immunofluorescence

268 Formalin-fixed, paraffin-embedded tissue sections were deparaffinized in xylene and rehydrated

269 in graded ethanol. Antigen retrieval was performed in a citrate buffer (pH 6.0). Sections were 270 then blocked with blocking buffer (10\% normal goat or donkey serum, 1\% bovine serum 271 albumin, $0.4 \%$ Triton X-100 in phosphate-buffered saline) for an hour and incubated overnight at $2724^{\circ} \mathrm{C}$ with primary antibodies against green fluorescent protein (cross-reactive with yellow 273 fluorescent protein) and insulin (Table S1). Nuclei were counterstained with 4',6-diamidino-2274 phenylindole (DAPI). TrueVIEW Autofluorescence Quenching Kit (Vector Laboratories, \#SP275 8400) was used according to the manufacturer's instructions to quench autofluorescence. 276 Epifluorescent images were obtained at a 40X magnification on an Olympus IX73 inverted 277 fluorescent microscope.

279 Serum enzyme and blood glucose detection

280 Serum amylase and lipase concentrations were determined at the Clinical Pathology core 281 facility at MD Anderson Cancer Center with an Integra 400 Plus (Roche Diagnostics). Serum 282 insulin and glucagon concentrations were measured according to the manufacturer's 283 instructions with an Ultra-Sensitive Mouse Insulin ELISA Kit (Crystal Chem, \#90080) and a 284 Mouse Glucagon ELISA Kit (Crystal Chem, \#81518).

285 For fasting blood glucose, mice were fasted for 4 hours and blood glucose was measured using 286 a Roche Diagnostics Accu-Chek Inform II glucometer. Oral glucose tolerance test was 287 performed as described previously (Andrikopoulos et al., 2008). Briefly, mice fasted overnight 288 (16h) and were given an oral bolus of $2 \mathrm{mg} / \mathrm{kg}$ of glucose. Retro-orbital blood was collected 15 
min and $1 \mathrm{~h}$ after glucose administration. Blood glucose and serum insulin were measured as

290 described above.

292 Fecal fat quantification

293 Protocol for fecal fat assessment was adapted from a previously described protocol (Drummey

294 et al., 1961). Briefly, $25 \mathrm{mg}$ of stool was added to a $1: 1$ solution of $95 \%$ ethanol and deionized

295 water, and vortexed. $25 \mu \mathrm{L}$ of supernatant was mixed with $10 \mu \mathrm{L}$ of a saturated solution of

296 SUDAN III (Sigma-Aldrich, \# S4131-25G) in 95\% ethanol. Fat globules were quantified (under

297 40X magnification) as the number of fat globules per field of view. A minimum of five different

298 fields were assessed, and the average number of fat globules per biological replicate was

299 reported.

\section{$300 \quad$ Flow cytometry}

301 Single cell splenocytes were isolated by passing the spleen through a $40 \mu \mathrm{m}$ mesh. Cells were

302 treated with Fixative-Free Lysing Solution, High-Yield Lyse (Invitrogen, \#HYL250) for RBC Iysis.

303 Samples were then stained with a Live/Dead Blue dye, followed by incubation with Fc Block (BD

304 Biosciences) and then stained with anti-mouse Nk1.1, Ly6G, Ly6C, CD19, CD11b, CD11c,

305 CD3, CD8, CD4, and CD45 antibodies (Table S1). Sample acquisition was performed on an

306 LSRFortessa X-20 Cell Analyzer flow cytometer (BD Biosciences). The analysis was performed

307 with FlowJo software, version 10 (FlowJo LLC). Results are expressed as relative percentage of

308 total gated live CD45 ${ }^{+}$cells.

310 RNA isolation and quantitative polymerase chain reaction (qPCR)

311 RNA was isolated using the Qiagen RNeasy Mini Kit and reverse transcribed using the

312 SuperScript III First-Strand Synthesis System (Invitrogen, \#18080-51). qPCR was performed

313 using SYBR Green PCR Master Mix (Lifetech, \#43-676-59) on a ViiA 7 Real-Time PCR System 
314 (Applied Biosystems). The primers used are listed in Table S2. Beta-2-microglobulin was used

315 for normalization. Assays were performed with 3 technical replicates.

\section{Statistical analysis}

318 All statistical analyses were performed using Prism software (GraphPad Software, Inc.). Data is

319 expressed as the mean plus or minus the standard error of the mean (SEM). Statistical

320 significance between two groups was assessed using a two-sample test, unless otherwise

321 noted. $p<0.05$ was considered statistically significant. Ns $=$ not significant, ${ }^{*}=p<0.05,{ }^{* \star *}=p<$

$3220.001^{* *}=p<0.01,^{\star * * *}=p<0.0001$.

\section{ACKNOWLEDGEMENTS}

327 We thank members of the Rhim and McAllister lab for critical reading of the manuscript, as well

328 as Laura L. Russell, scientific editor, Research Medical Library, for helpful editorial review. We

329 also thank the technical staff at the Clinical Pathology core facility and the Flow Cytometry and

330 Cellular Imaging Core Facility at MD Anderson Cancer Center for their help and expertise. This

331 shared resource is partially funded by NCI Cancer Center Support Grant P30CA16672.

333 COMPETING INTERESTS: Authors have no conflict of interests to disclose.

\section{FUNDING}

336 F.M. received support from the V Foundation (Translational Award), NCI R37 (CA237384) and

337 Cancer Prevention and Research Institute of Texas (RP200173), A.R. is supported by the MD

338 Anderson Cancer Center (Physician Scientist Program) and Cancer Prevention and Research

339 Institute of Texas (Rising Stars Award, \# RR160022). A.R. and F.M. have been supported by 
340 the Andrew Sabin Family Foundation and MD Anderson Philanthropic funding. P.M is supported

341 by funding from the Jane Coffin Childs Medical Trust Fund and the American Society of

342 Hematology.

\section{REFERENCES}

AHMAD, S., MU, X., YANG, F., GREENWALD, E., PARK, J. W., JACOB, E., ZHANG, C. Z. \& HUR, S. 2018. Breaching Self-Tolerance to Alu Duplex RNA Underlies MDA5-Mediated Inflammation. Cell, 172, 797-810 e13.

ANDRIKOPOULOS, S., BLAIR, A. R., DELUCA, N., FAM, B. C. \& PROIETTO, J. 2008. Evaluating the glucose tolerance test in mice. Am J Physiol Endocrinol Metab, 295, E1323-32.

BAHN, J. H., AHN, J., LIN, X., ZHANG, Q., LEE, J. H., CIVELEK, M. \& XIAO, X. 2015. Genomic analysis of ADAR1 binding and its involvement in multiple RNA processing pathways. Nat Commun, 6, 6355.

BAJAD, P., EBNER, F., AMMAN, F., SZABO, B., KAPOOR, U., MANJALI, G., HILDEBRANDT, A., JANISIW, M. P. \& JANTSCH, M. F. 2020. An internal deletion of ADAR rescued by MAVS deficiency leads to a minute phenotype. Nucleic Acids Res, 48, 3286-3303.

BEN-SHOSHAN, S. O., KAGAN, P., SULTAN, M., BARABASH, Z., DOR, C., JACOB-HIRSCH, J., HARMELIN, A., PAPPO, O., MARCU-MALINA, V., BEN-ARI, Z., AMARIGLIO, N., RECHAVI, G., GOLDSTEIN, I. \& SAFRAN, M. 2017. ADAR1 deletion induces NFkappaB and interferon signaling dependent liver inflammation and fibrosis. RNA Biol, 14, 587-602.

BRINKM ANN, V., GEIGER, T., ALKAN, S. \& HEUSSER, C. H. 1993. Interferon alpha increases the frequency of interferon gamma-producing human CD4+ T cells. J Exp Med, 178, 1655-63.

CANO, D. A., HEBROK, M. \& ZENKER, M. 2007. Pancreatic development and disease. Gastroenterology, $132,745-62$.

CROW, Y. J. \& MANEL, N. 2015. Aicardi-Goutieres syndrome and the type I interferonopathies. Nat Rev Immunol, 15, 429-40.

DRUMMEY, G. D., BENSON, J. A., JR. \& JONES, C. M. 1961. Microscopical examination of the stool for steatorrhea. N Engl J Med, 264, 85-7. 
EISENBERG, E. \& LEVANON, E. Y. 2018. A-to-I RNA editing - immune protector and transcriptome diversifier. Nat Rev Genet, 19, 473-490.

GACEM, N., KAVO, A., ZERAD, L., RICHARD, L., MATHIS, S., KAPUR, R. P., PARISOT, M., AMIEL, J., DUFOUR, S., DE LA GRANGE, P., PINGAULT, V., VALLAT, J. M. \& BONDURAND, N. 2020. ADAR1 mediated regulation of neural crest derived melanocytes and Schwann cell development. Nat Commun, 11, 198.

GALICIA-GARCIA, U., BENITO-VICENTE, A., JEBARI, S., LARREA-SEBAL, A., SIDDIQI, H., URIBE, K. B., OSTOLAZA, H. \& MARTIN, C. 2020. Pathophysiology of Type 2 Diabetes Mellitus. Int J Mol Sci, 21.

GRAPIN-BOTTON, A. 2005. Ductal cells of the pancreas. Int J Biochem Cell Biol, 37, 504-10.

HARTNER, J. C., SCHMITTWOLF, C., KISPERT, A., MULLER, A. M., HIGUCHI, M. \& SEEBURG, P. H. 2004. Liver disintegration in the mouse embryo caused by deficiency in the RNA-editing enzyme ADAR1. J Biol Chem, 279, 4894-902.

HARTNER, J. C., WALKLEY, C. R., LU, J. \& ORKIN, S. H. 2009. ADAR1 is essential for the maintenance of hematopoiesis and suppression of interferon signaling. Nat Immunol, 10, 109-15.

KAWAGUCHI, Y., COOPER, B., GANNON, M., RAY, M., MACDONALD, R. J. \& WRIGHT, C. V. 2002. The role of the transcriptional regulator Ptf1a in converting intestinal to pancreatic progenitors. Nat Genet, 32, 128-34.

KIM, U., WANG, Y., SANFORD, T., ZENG, Y. \& NISHIKURA, K. 1994. Molecular cloning of cDNA for doublestranded RNA adenosine deaminase, a candidate enzyme for nuclear RNA editing. Proc Natl Acad Sci U S A, 91, 11457-61.

LEE, P. J. \& PAPACHRISTOU, G. I. 2019. New insights into acute pancreatitis. Nat Rev Gastroenterol Hepatol, 16, 479-496.

LEWIS, S. M., WILLIAMS, A. \& EISENBARTH, S. C. 2019. Structure and function of the immune system in the spleen. Sci Immunol, 4.

LIDDICOAT, B. J., HARTNER, J. C., PISKOL, R., RAMASWAMI, G., CHALK, A. M., KINGSLEY, P. D., SANKARAN, V. G., WALL, M., PURTON, L. E., SEEBURG, P. H., PALIS, J., ORKIN, S. H., LU, J., LI, J. B. \& WALKLEY, C. R. 2016. Adenosine-to-inosine RNA editing by ADAR1 is essential for normal murine erythropoiesis. Exp Hematol, 44, 947-63.

LIDDICOAT, B. J., PISKOL, R., CHALK, A. M., RAMASWAMI, G., HIGUCHI, M., HARTNER, J. C., LI, J. B., SEEBURG, P. H. \& WALKLEY, C. R. 2015. RNA editing by ADAR1 prevents MDA5 sensing of endogenous dsRNA as nonself. Science, 349, 1115-20.

LINDKVIST, B. 2013. Diagnosis and treatment of pancreatic exocrine insufficiency. World J Gastroenterol, 19, 7258-66.

LIU, M., LIANG, S. \& ZHANG, C. 2021. NK Cells in Autoimmune Diseases: Protective or Pathogenic? Front Immunol, 12, 624687.

MADERA, S., RAPP, M., FIRTH, M. A., BEILKE, J. N., LANIER, L. L. \& SUN, J. C. 2016. Type I IFN promotes NK cell expansion during viral infection by protecting NK cells against fratricide. J Exp Med, 213, 225-33.

MAGNUSON, M. A. \& OSIPOVICH, A. B. 2013. Pancreas-specific Cre driver lines and considerations for their prudent use. Cell Metab, 18, 9-20.

MANNION, N. M., GREENWOOD, S. M., YOUNG, R., COX, S., BRINDLE, J., READ, D., NELLAKER, C., VESELY, C., PONTING, C. P., MCLAUGHLIN, P. J., JANTSCH, M. F., DORIN, J., ADAMS, I. R., SCADDEN, A. D., OHMAN, M., KEEGAN, L. P. \& O'CONNELL, M. A. 2014. The RNA-editing enzyme ADAR1 controls innate immune responses to RNA. Cell Rep, 9, 1482-94.

MCNAB, F., MAYER-BARBER, K., SHER, A., WACK, A. \& O'GARRA, A. 2015. Type I interferons in infectious disease. Nat Rev Immunol, 15, 87-103.

MELCHER, T., MAAS, S., HERB, A., SPRENGEL, R., SEEBURG, P. H. \& HIGUCHI, M. 1996. A mammalian RNA editing enzyme. Nature, 379, 460-4. 
OTA, H., SAKURAI, M., GUPTA, R., VALENTE, L., WULFF, B. E., ARIYOSHI, K., IIZASA, H., DAVULURI, R. V. \& NISHIKURA, K. 2013. ADAR1 forms a complex with Dicer to promote microRNA processing and RNA-induced gene silencing. Cell, 153, 575-89.

PALMER, M. T. \& WEAVER, C. T. 2010. Autoimmunity: increasing suspects in the CD4+ T cell lineup. Nat Immunol, 11, 36-40.

PANDIRI, A. R. 2014. Overview of exocrine pancreatic pathobiology. Toxicol Pathol, 42, 207-16.

PATTERSON, J. B. \& SAMUEL, C. E. 1995. Expression and regulation by interferon of a double-strandedRNA-specific adenosine deaminase from human cells: evidence for two forms of the deaminase. Mol Cell Biol, 15, 5376-88.

PESTAL, K., FUNK, C. C., SNYDER, J. M., PRICE, N. D., TREUTING, P. M. \& STETSON, D. B. 2015. Isoforms of RNA-Editing Enzyme ADAR1 Independently Control Nucleic Acid Sensor MDA5-Driven Autoimmunity and Multi-organ Development. Immunity, 43, 933-44.

RHIM, A. D., MIREK, E. T., AIELLO, N. M., MAITRA, A., BAILEY, J. M., MCALLISTER, F., REICHERT, M., BEATTY, G. L., RUSTGI, A. K., VONDERHEIDE, R. H., LEACH, S. D. \& STANGER, B. Z. 2012. EMT and dissemination precede pancreatic tumor formation. Cell, 148, 349-61.

ROUNDTREE, I. A., EVANS, M. E., PAN, T. \& HE, C. 2017. Dynamic RNA Modifications in Gene Expression Regulation. Cell, 169, 1187-1200.

SKAPENKO, A., LEIPE, J., LIPSKY, P. E. \& SCHULZE-KOOPS, H. 2005. The role of the T cell in autoimmune inflammation. Arthritis Res Ther, 7 Suppl 2, S4-14.

SRINIVAS, S., WATANABE, T., LIN, C. S., WILLIAM, C. M., TANABE, Y., JESSELL, T. M. \& COSTANTINI, F. 2001. Cre reporter strains produced by targeted insertion of EYFP and ECFP into the ROSA26 locus. BMC Dev Biol, 1, 4.

SUN, Q., SUN, L., LIU, H. H., CHEN, X., SETH, R. B., FORMAN, J. \& CHEN, Z. J. 2006. The specific and essential role of MAVS in antiviral innate immune responses. Immunity, 24, 633-42.

VONGPIPATANA, T., NAKAHAMA, T., SHIBUYA, T., KATO, Y. \& KAWAHARA, Y. 2020. ADAR1 Regulates Early T Cell Development via MDA5-Dependent and -Independent Pathways. J Immunol, 204, 2156-2168.

WANG, G., WANG, H., SINGH, S., ZHOU, P., YANG, S., WANG, Y., ZHU, Z., ZHANG, J., CHEN, A., BILLIAR, T., MONGA, S. P. \& WANG, Q. 2015. ADAR1 Prevents Liver Injury from Inflammation and Suppresses Interferon Production in Hepatocytes. Am J Pathol, 185, 3224-37.

WANG, Q., MIYAKODA, M., YANG, W., KHILLAN, J., STACHURA, D. L., WEISS, M. J. \& NISHIKURA, K. 2004. Stress-induced apoptosis associated with null mutation of ADAR1 RNA editing deaminase gene. $J$ Biol Chem, 279, 4952-61.

WARD, S. V., GEORGE, C. X., WELCH, M. J., LIOU, L. Y., HAHM, B., LEWICKI, H., DE LA TORRE, J. C., SAMUEL, C. E. \& OLDSTONE, M. B. 2011. RNA editing enzyme adenosine deaminase is a restriction factor for controlling measles virus replication that also is required for embryogenesis. Proc Natl Acad Sci U S A, 108, 331-6. 


\section{FIGURE LEGENDS}

Figure 1. Conditional knockout of Adar1 in the pancreas leads to a runted phenotype. (A) Schematic of the Ptf1 $a^{\text {Cre/+ }}$ Rosa26 ${ }^{\text {LSL-YFP }}$ Adar1 $1^{\mathrm{Fl} / F I}$ (CYA) mouse model. (B) Control and CYA pancreases were assayed for Adar1 recombination at birth. (C) Representative images of control and CYA mice. (D) Body mass of control and CYA mice at D0, D10 and D21. (E) Representative images of pancreases from control and CYA mice at D10 (top) and D21 (bottom). (F) Relative pancreatic mass (\% pancreas/body mass) at D0, D10 and D21. (G) Relative spleen (left) and kidney (right) mass of control and CYA mice at D10 and D21. (H) Immunofluorescence exhibiting insulin and YFP in control and CYA pancreata at D21. Scale bar: $50 \mu \mathrm{M}$. (I) Quantification of $\mathrm{YFP}^{+}$area in $(\mathrm{H})$.

Figure 2. Adar1 deletion results in loss of acinar cells and pancreatitis. (A) Histology of control and CYA pancreases at embryonic day 18.5 (E18.5), D2, D10 and D21. (B) Quantification of acinar cell area in (A). (C) Control and CYA pancreases at D10 assayed for keratin19 $\left(\right.$ Ck19) ${ }^{+}$clusters (red arrows) and (D) its quantification. (E) Representative images and (F) quantification of amylase ${ }^{+}$area in control and CYA pancreata. (G) Representative images and $\mathbf{( H )}$ quantification of apoptotic nuclei (red arrows) in control and CYA pancreases. (I) Representative images and (J) quantification of CD45 cells (red arrows) in control and CYA pancreata. Scale bar: $100 \mu \mathrm{M}$.

Figure 3. Concurrent Mavs knockout can rescue the runted phenotype of the CYA mice. (A) Quantitative PCR (qPCR) for a panel of interferon-stimulated genes (ISGs) from control and CYA pancreata at D2. (B) qPCR for ISGs from control and CYAM pancreata at 2 months. (C) Representative images and (D) quantification of body mass of control and CYAM mice at 6 months. (E) Representative images and (F) quantification of relative pancreatic mass of control and CYAM mice at 6 months. (G) Pancreases from control and CYAM mice were assayed for 
Adar1 recombination. (H) Representative images of control and CYAM pancreases and (I) quantification of acinar cell area. (J) Representative images of apoptotic nuclei and (K, L) $\mathrm{CD}^{+} 5^{+}$(red arrows) cells in control and CYAM pancreases. Scale bar: $100 \mu \mathrm{M}$.

Figure 4. Co-deletion of Mavs can restore pancreatic function. Representative images of (A) amylase $^{+}$and (B) insulin ${ }^{+}$area and (C, D) their respective quantification. Scale bar: $100 \mu \mathrm{M}$. (E) Serum lipase, (F) amylase, and (G) glucagon concentration in control and CYAM mice. (H) Serum insulin and (I) blood glucose concentration, 15 and 60 mins post-oral glucose administration. (J) Representative images of control and CYAM fecal fat assayed for fat globules with SUDAN III. Scale bar: $50 \mu \mathrm{M}$. 
bioRxiv preprint doi: https://doi.org/10.1101/2021.11.03.467127; this version posted November 4, 2021. The copyright holder for this preprint (which was not certified by peer review) is the author/funder. All rights reserved. No reuse allowed without permission. 
A

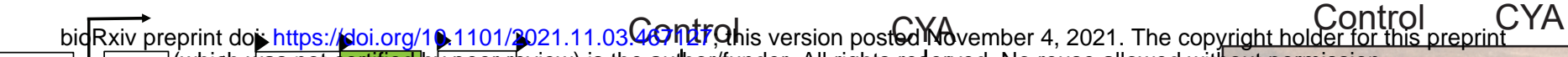

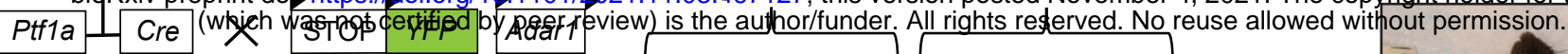

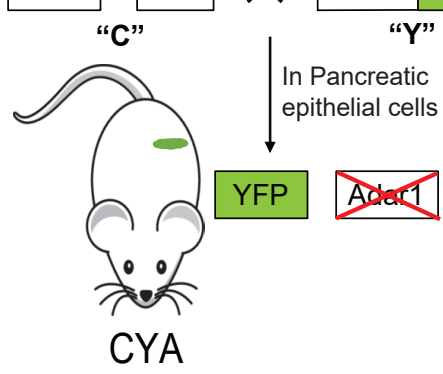

D

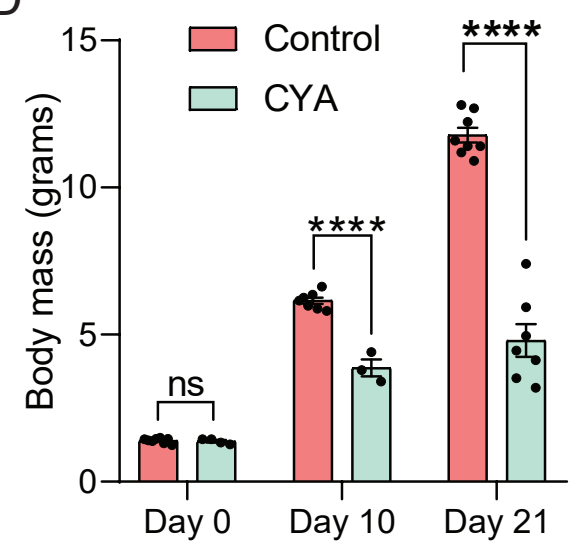

F

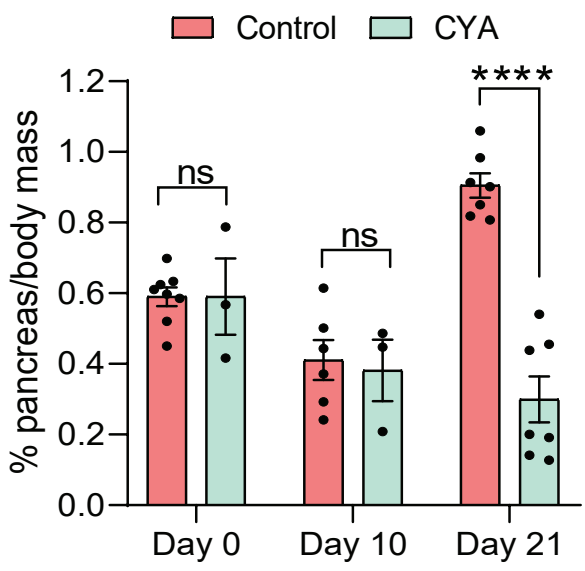

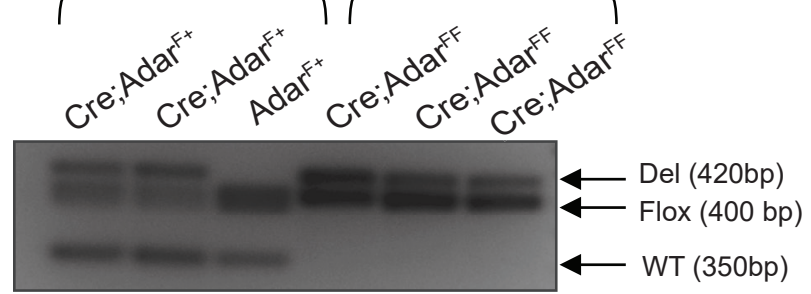

E

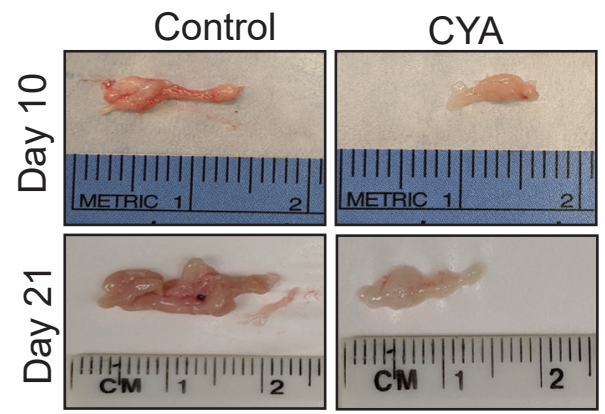

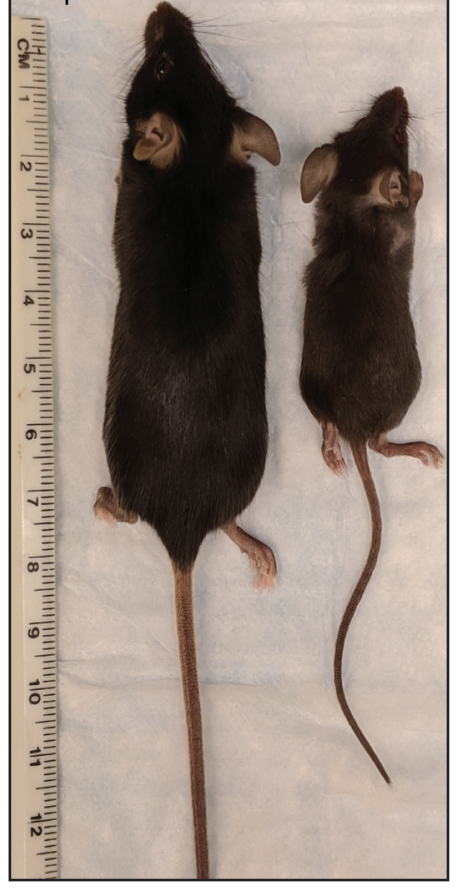

G
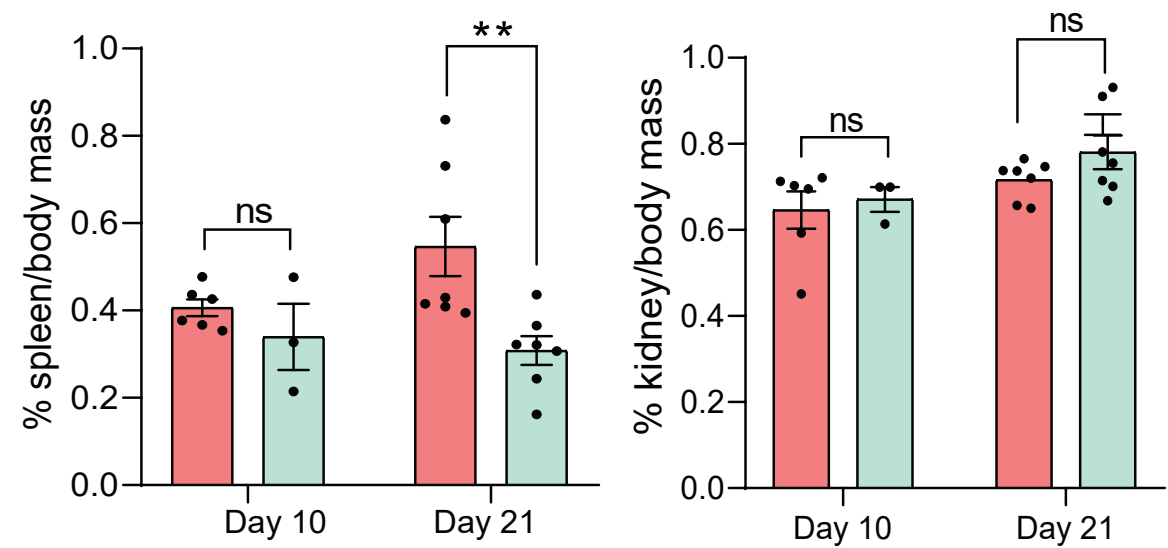

$\mathrm{H}$
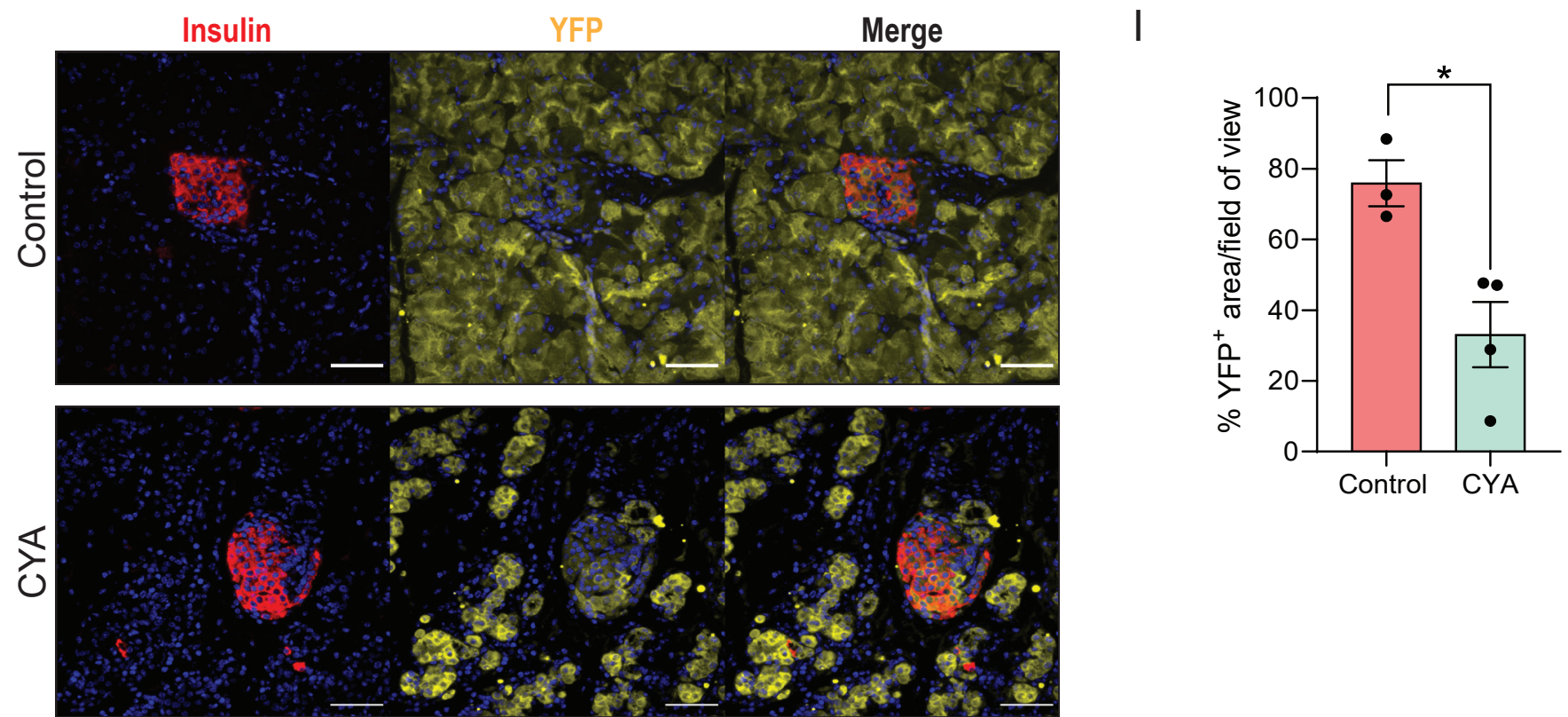
Fiqure 2 bioky preprint doi: https://doi.org/10.1101/2021.11.03.467127; this version posted November 4, 2021. The copyright holder for this preprint
(which was not certified by peer review) is the author/funder. All rights reserved. No reuse allowed without permission.

A
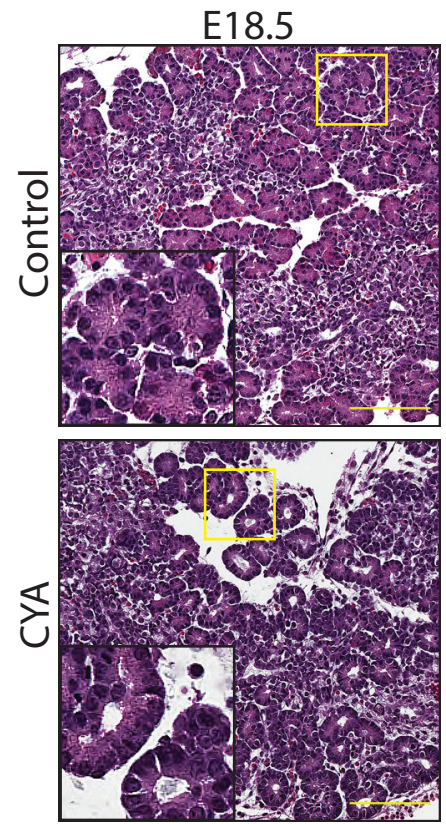

B

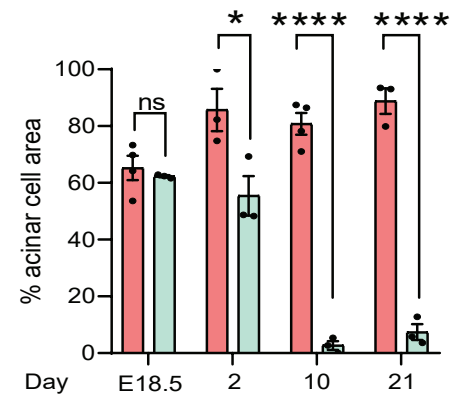

E18.5

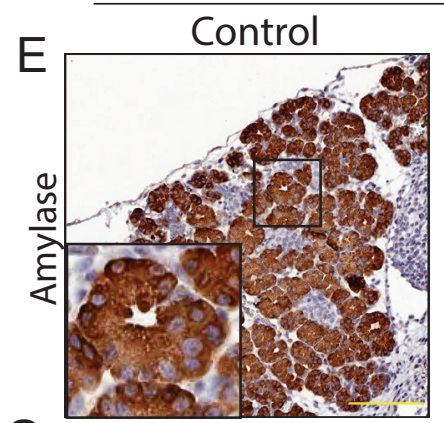

G
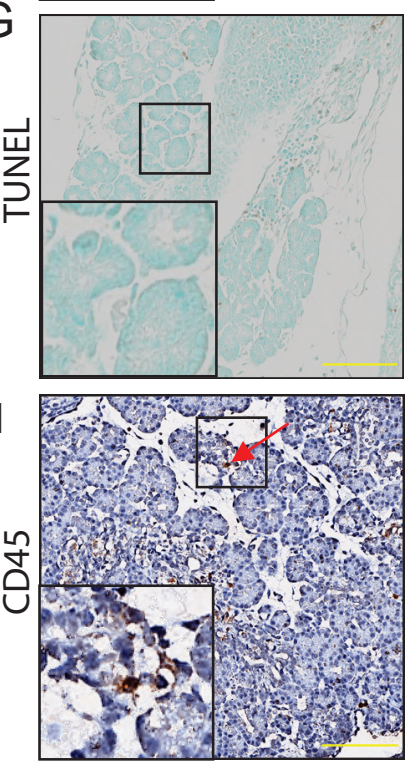

Day 2
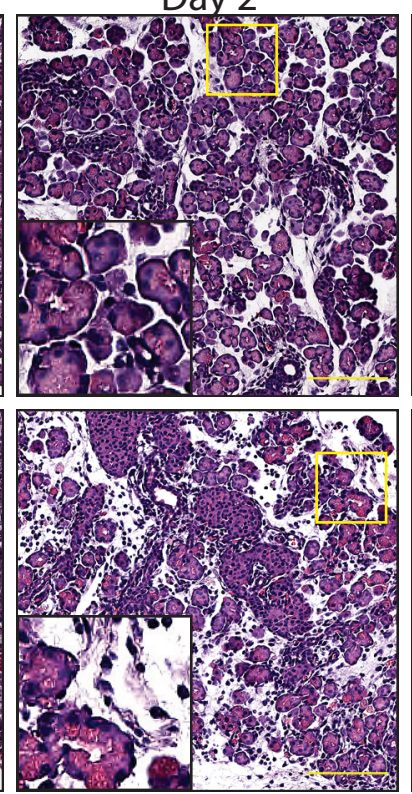

C

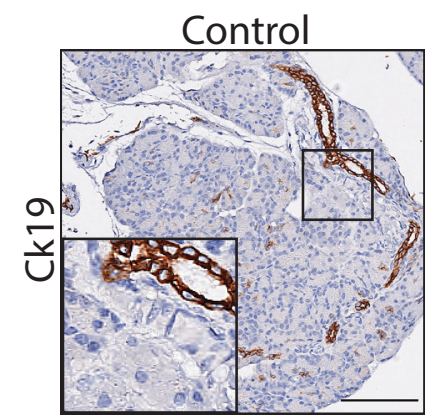

Day 10
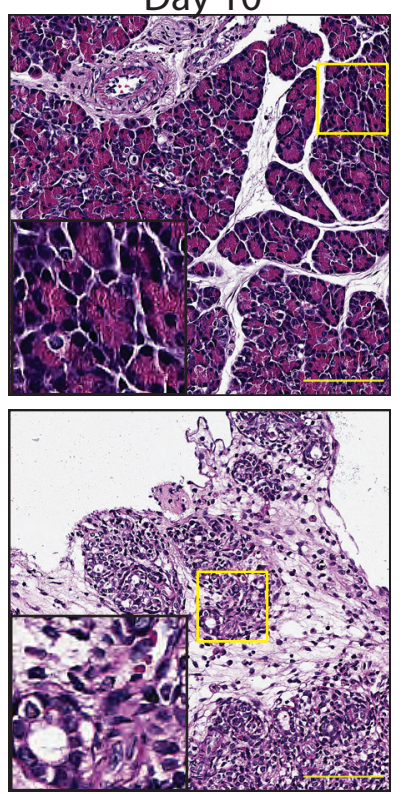

Day 21
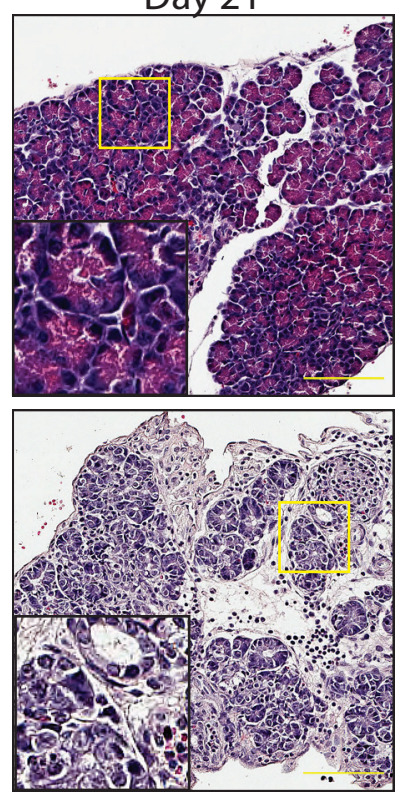

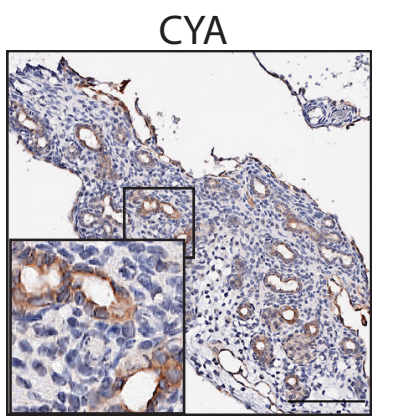

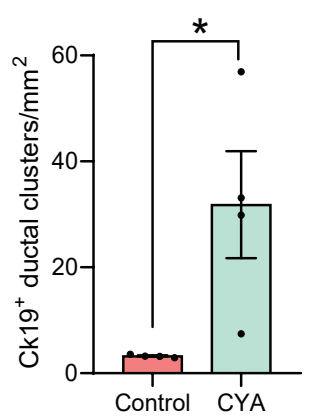

Day 21
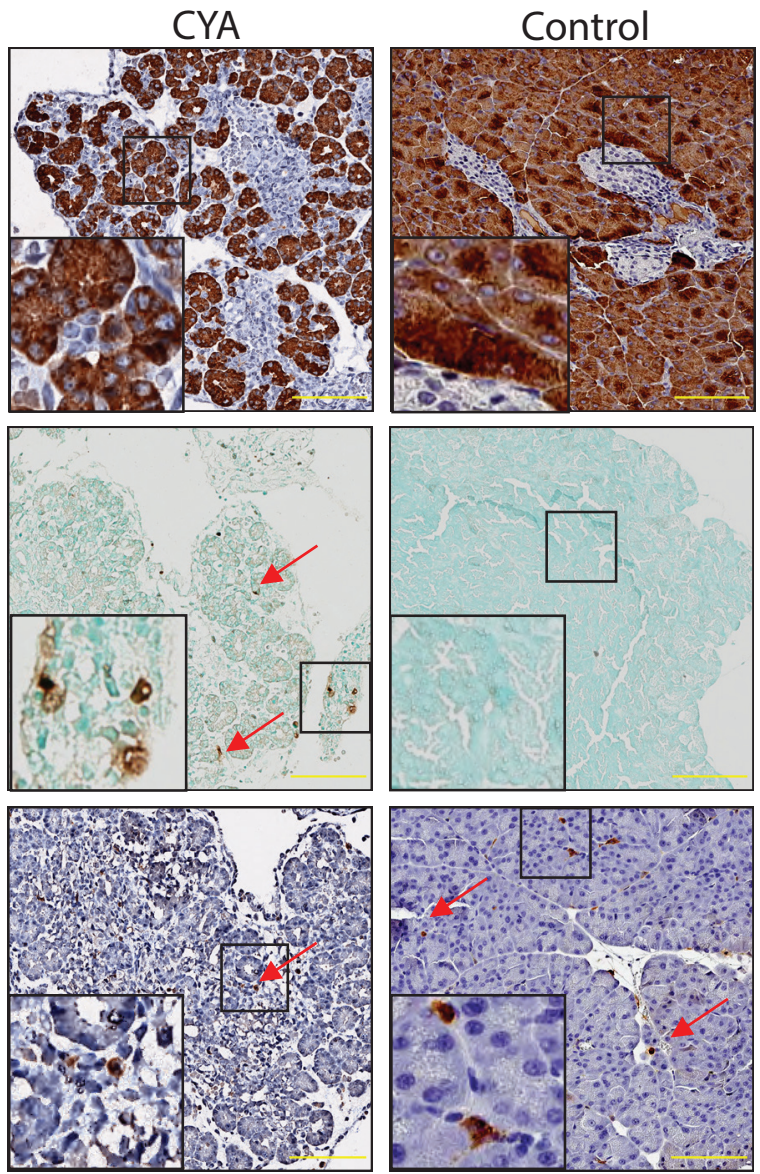
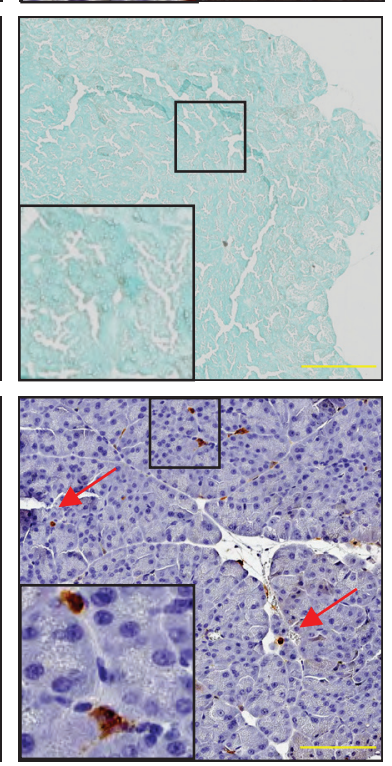
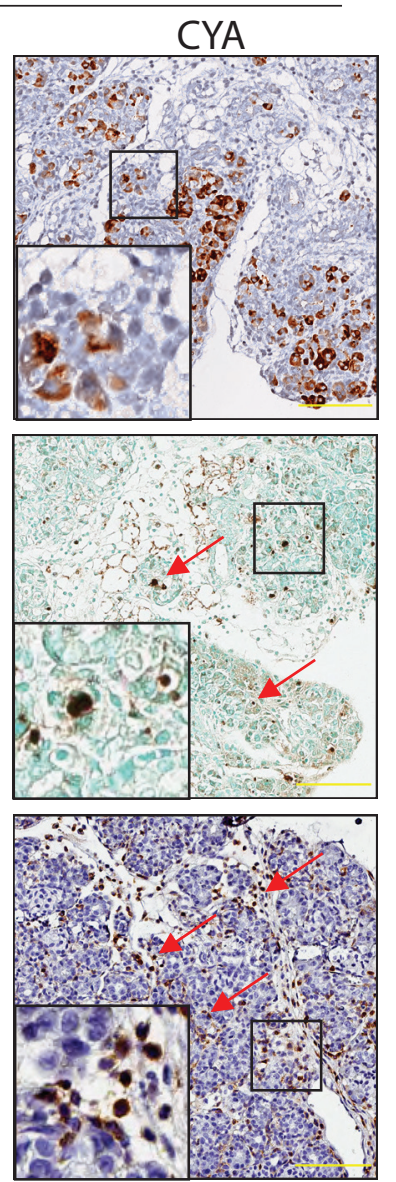

$\mathrm{F}$

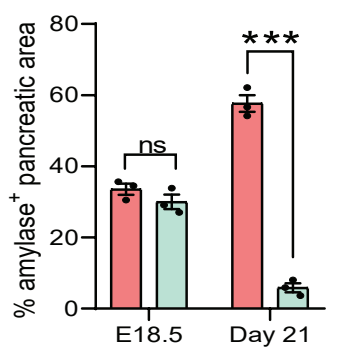

$\mathrm{H}$

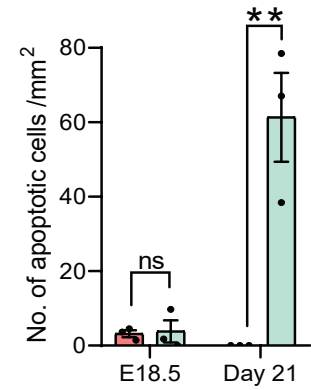

$\mathrm{J}$ 
Figure 3

A

C 6 months

bioRxiv preprint doi: https://doi.org/10.1101/2021.11.03.467127; this version posted November 4, 2021. Theontrol CYAM

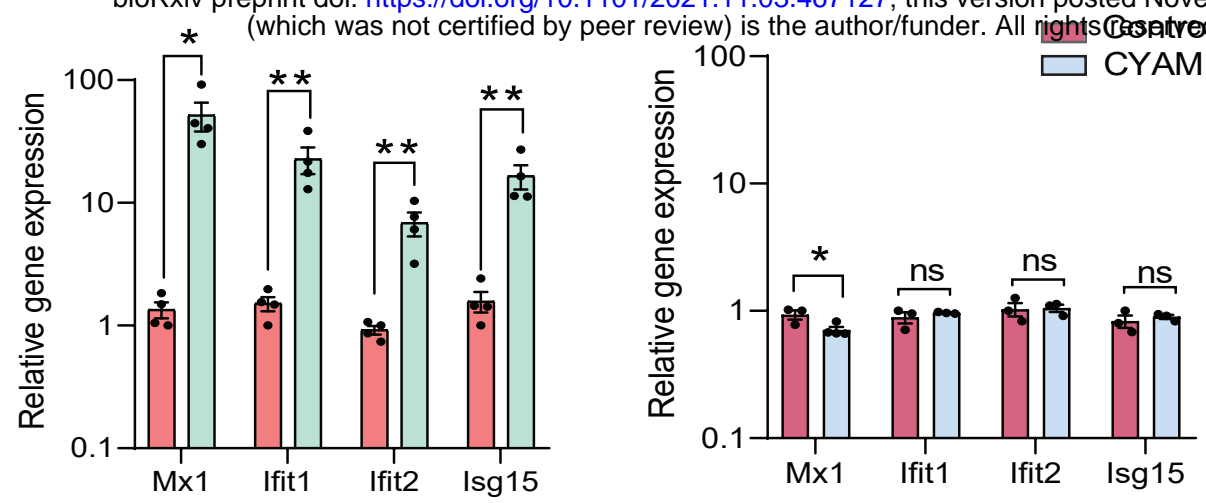

D

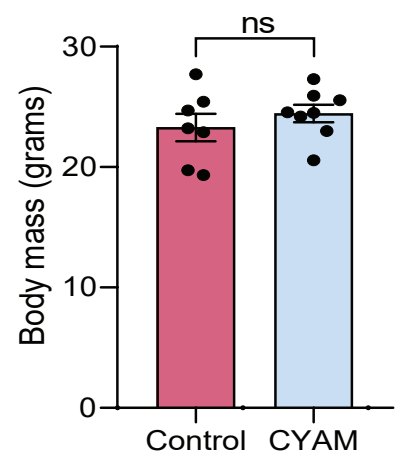

E

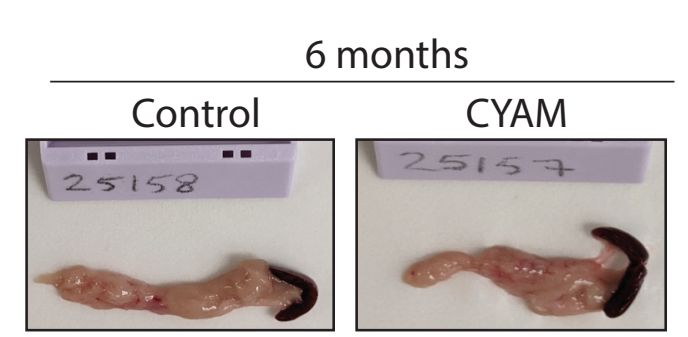

$\mathrm{F}$

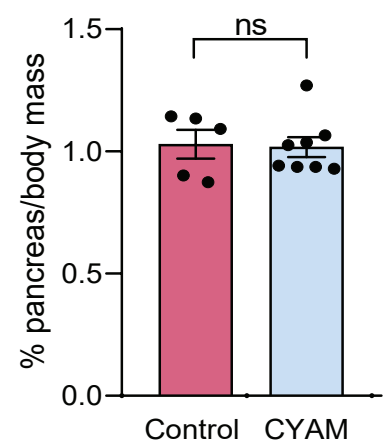

G

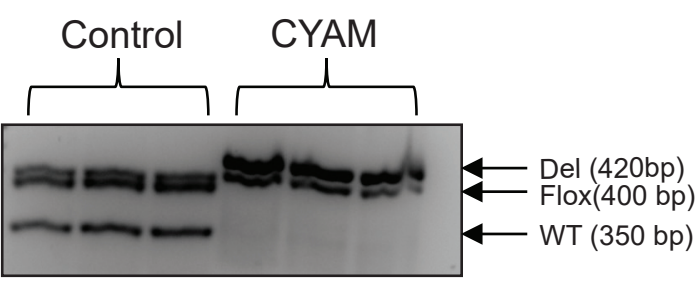

$\mathrm{H}$
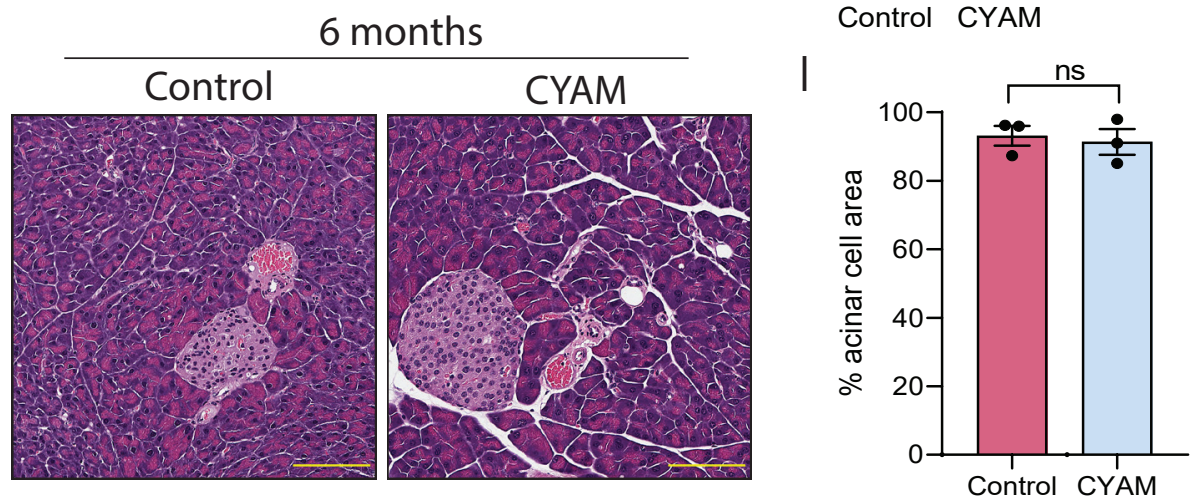

J

6 months
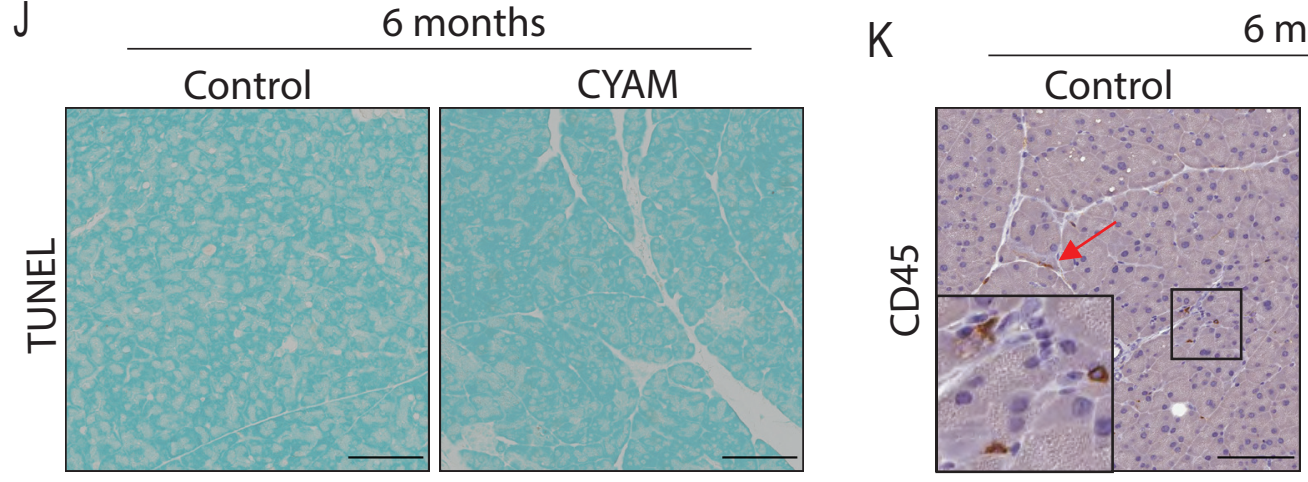

6 months
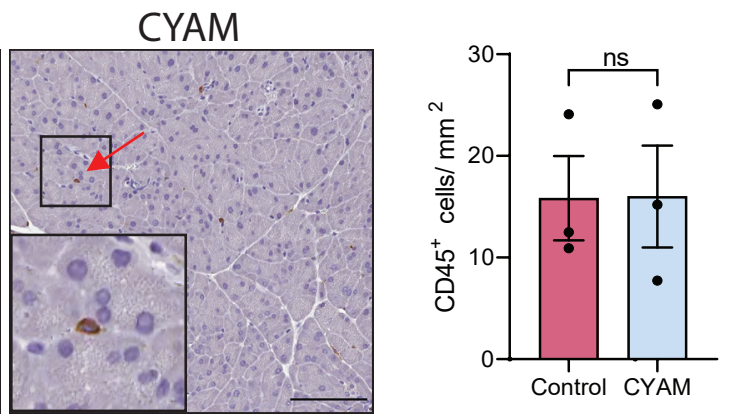
Figure 4

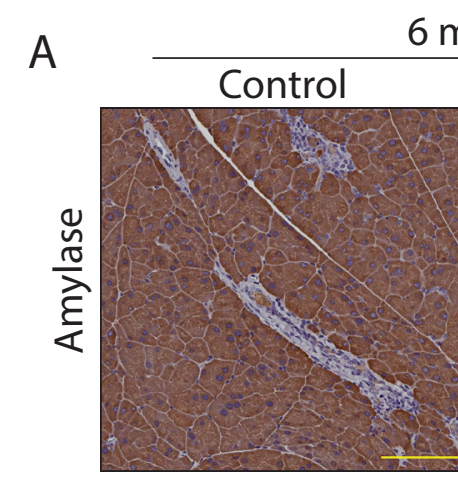

6 months

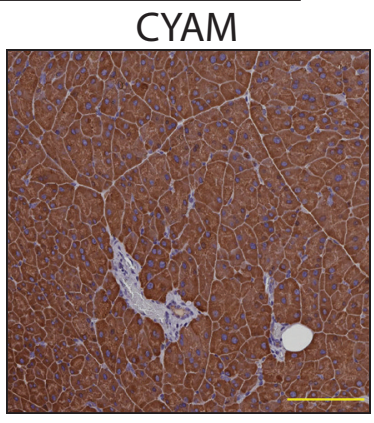

E

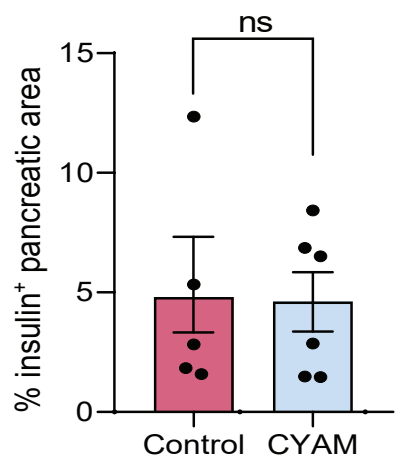

$\mathrm{H}$

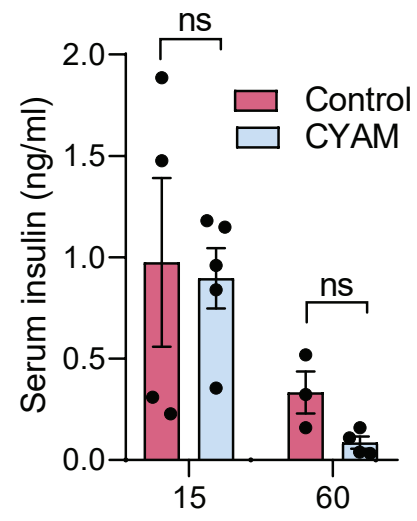

Time (min)

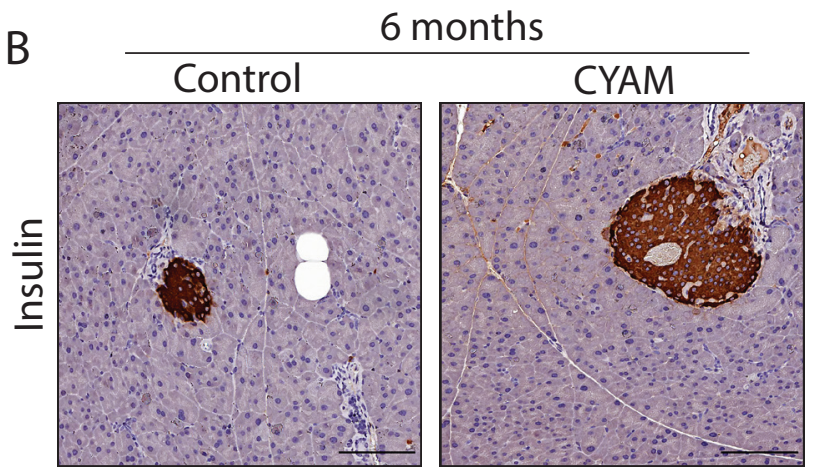

C

F
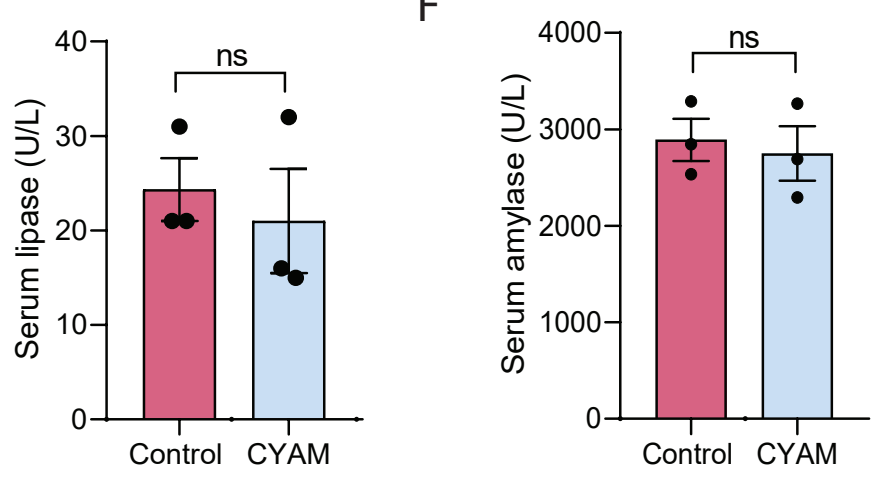

G
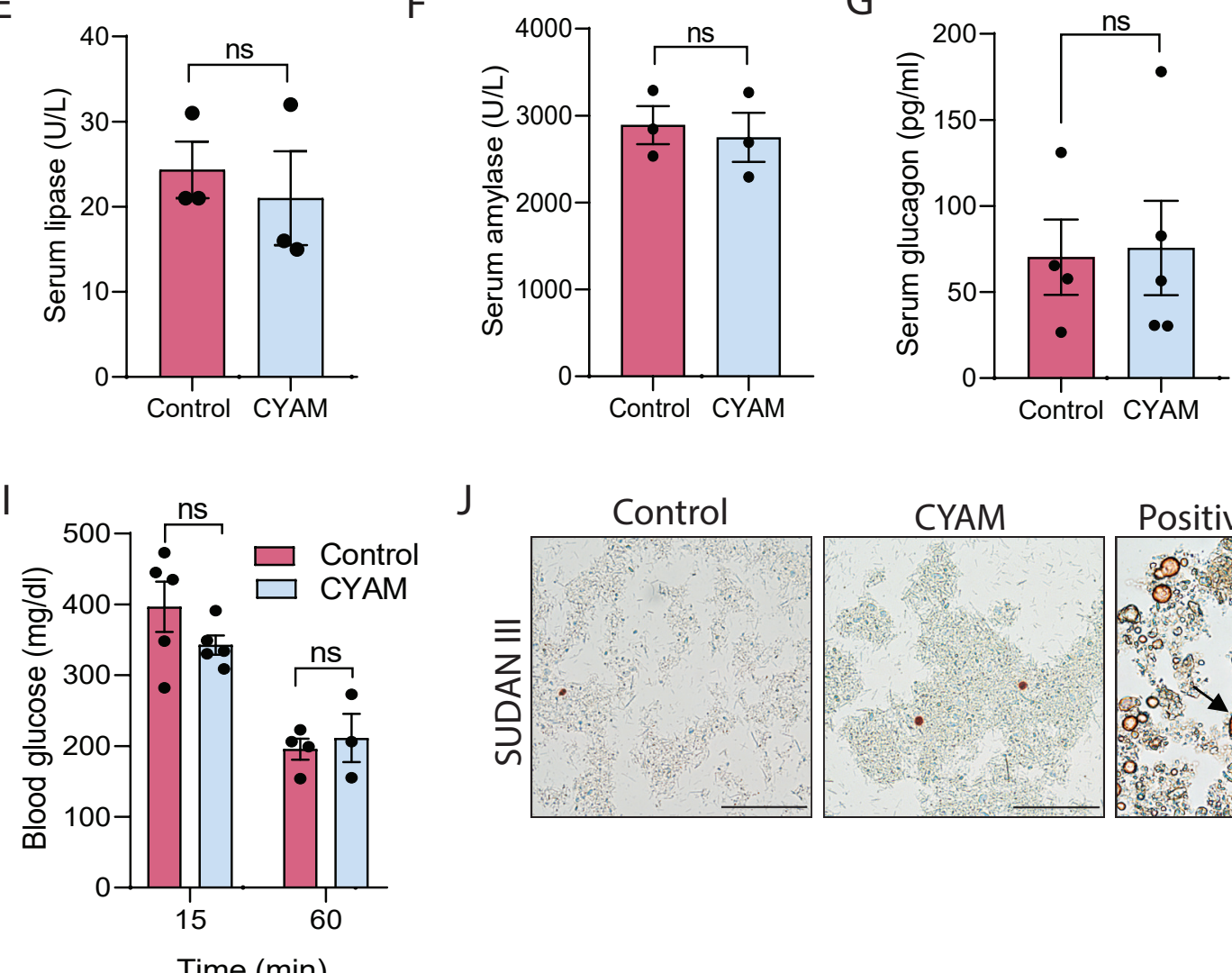

J

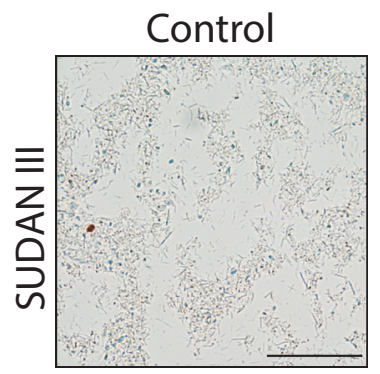

CYAM

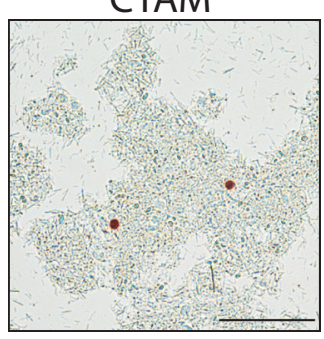

Positive control

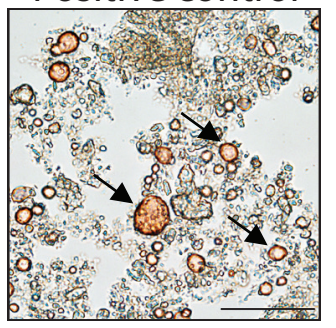

